\title{
Small-Animal PET of Tumor Damage Induced by Photothermal Ablation with ${ }^{64} \mathrm{Cu}$-Bis-DOTA-Hypericin
}

\author{
Shaoli Song*1,2, Chiyi Xiong*1, Min Zhou ${ }^{1}$, Wei Lu ${ }^{1}$, Qian Huang ${ }^{1}$, Geng Ku ${ }^{1}$, Jun Zhao ${ }^{1}$, Leo G. Flores, Jr. ${ }^{1}$, \\ Yicheng $\mathrm{Ni}^{3}$, and Chun $\mathrm{Li}^{1}$ \\ ${ }^{1}$ Department of Experimental Diagnostic Imaging, University of Texas M.D. Anderson Cancer Center, Houston, Texas; ${ }^{2}$ Department \\ of Nuclear Medicine, Renji Hospital, Shanghai Jiaotong University, School of Medicine, Shanghai, China; and ${ }^{3}$ Department of \\ Radiology; University Hospitals, K.U. Leuven, Leuven, Belgium
}

The purpose of this study was to investigate the potential application of small-molecular-weight ${ }^{64} \mathrm{Cu}$-labeled bis-DOTAhypericin in the noninvasive assessment of response to photothermal ablation therapy. Methods: Bis-DOTA-hypericin was labeled with ${ }^{64} \mathrm{Cu}$ with high efficiency $(>95 \%$ without purification). Nine mice bearing subcutaneous human mammary BT474 tumors were used. Five mice were injected intratumorally with semiconductor CuS nanoparticles, followed by near-infrared laser irradiation $24 \mathrm{~h}$ later $\left(12 \mathrm{~W} / \mathrm{cm}^{2}\right.$ for $\left.3 \mathrm{~min}\right)$, and 4 mice were not treated (control group). All mice were intravenously injected with ${ }^{64} \mathrm{Cu}$-bis-DOTA-hypericin $(24 \mathrm{~h}$ after laser treatment in treated mice). Small-animal PET images were acquired at 2,6 , and $24 \mathrm{~h}$ after radiotracer injection. All mice were killed immediately after the imaging session for biodistribution and histology study. In vitro cell uptake and surface plasmon resonance studies were performed to validate the small-animal PET results. Results: ${ }^{64} \mathrm{Cu}$-bis-DOTA-hypericin uptake was significantly higher in the treatment group than in the control group. The percentage injected dose per gram of tissue in the treated and control groups was $1.72 \pm 0.43$ and $0.76 \pm 0.19$, respectively $(P=0.017)$, at $24 \mathrm{~h}$ after injection. Autoradiography and histology results were consistent with selective uptake of the radiotracer in the necrotic zone of the tumor induced by photothermal ablation therapy. In vitro results showed that treated BT474 cells had a higher uptake of ${ }^{64} \mathrm{Cu}$-bis-DOTA-hypericin than nontreated cells. Surface plasmon resonance study showed that bis-DOTA-hypericin had higher binding affinity to phosphatidylserine and phosphatidylethanolamine than to phosphatidylcholine. Conclusion: ${ }^{64} \mathrm{Cu}$-bis-DOTA-hypericin has a potential to image thermal therapy-induced tumor cell damage. The affinity of ${ }^{64} \mathrm{Cu}$-bis-DOTA-hypericin for injured tissues may be attributed to the breakdown of the cell membrane and exposure of phosphatidylserine or phosphatidylethanolamine to the radiotracer, which binds selectively to these phospholipids.

\footnotetext{
Received Nov. 30, 2010; revision accepted Jan. 31, 2011.

For correspondence or reprints contact: Chun Li, Department of Experimental Diagnostic Imaging, Unit 59, University of Texas M.D. Anderson Cancer Center, 1515 Holcombe Blvd., Houston, TX 77030.

E-mail: cli@mdanderson.org

${ }^{*}$ Contributed equally to this work.

COPYRIGHT @ 2011 by the Society of Nuclear Medicine, Inc.
}

Key Words: hypericin; neoplasm; cell damage; near-infrared (NIR); photothermal ablation therapy; positron emission tomography

J Nucl Med 2011; 52:792-799

DOI: 10.2967/jnumed.110.086116

\section{$\mathbf{T}$} he fundamental problem of cancer treatment is the recurrence of resistant phenotypes. Most cancers, over time, develop resistance to chemotherapy and radiotherapy and subsequently give rise to metastatic tumors that inevitably are fatal. In addition to the obvious need to develop more efficient and cancer cell-specific drugs, the development of new treatment modalities that can potentially overcome resistance through a mechanism completely different from that of traditional therapies is highly desirable.

Phototherapy is the use of electromagnetic radiation to treat various medical conditions, including cancer (1). This new type of cancer therapy is gaining popularity because it delivers a specific amount of energy directly into the tumor mass through the use of skin-penetrating near-infrared (NIR) (wavelength, 700-1,065 nm) irradiation. This laser energy delivered to the targeted tumors can induce localized photochemical, photomechanical, and photothermal reactions that kill the tumor cells (2). In photothermal ablation (PTA), heat generated through the absorption of light is used to directly destroy cancer cells (3).

PTA is attractive because it is a locoregional physical treatment and, therefore, should have fewer side effects than conventional cancer treatments. PTA may also be performed repeatedly without the accumulation of toxic side effects and resistance. The efficiency of PTA can be significantly enhanced when a light-absorbing material is applied to the target tissue to mediate selective photothermal effects (4). Various gold nanostructures, including nanoshells, nanorods, and nanocages, which absorb NIR light, have been shown to be effective photothermal coupling agents (5-8). Recently, a new class of semiconductor nanostructure $\mathrm{CuS}$ nanoparticles suitable for PTA was introduced $(9,10)$. These nanoparticles were simple to make, possessed 
excellent stability, and were much smaller than gold nanostructures. Furthermore, $\mathrm{CuS}$ nanoparticles displayed strong absorption in the NIR region (peak, 900-930 nm) and mediated the ablation of tumor cells on exposure to NIR light both in vitro and in vivo after either intratumoral or intravenous injection.

Despite the great promise of PTA, some critical issues associated with its clinical translation remain to be addressed to fully realize the therapeutic potential of this treatment modality. For example, how much NIR flux (or laser dose) is required, and how many nanoparticles are needed to obliterate tumor cells without adversely affecting surrounding normal cells? What happens at the molecular and cellular levels at different stages of PTA? And how can response to PTA, particularly at an early stage of treatment, be monitored noninvasively and repeatedly with high accuracy?

Evaluation of the therapeutic effects of PTA in the clinic is currently based on anatomic imaging such as CT, MRI, or ultrasonography (e.g., Response Evaluation Criteria in Solid Tumors of the World Health Organization). However, morphologic changes usually do not occur until 2-3 mo after the start of treatment, and furthermore, volume measurements can be hampered by necrotic tissue or scar formation. PET using ${ }^{18}$ F-FDG has long been recognized as a tool for therapy response assessment, revealing highly predictive values only $1-2 \mathrm{wk}$ after the start of a therapy $(11,12)$. The use of PET to measure therapeutic response has many advantages over biopsy- and surrogate tissuebased measurements, including the direct measurement of heterogeneous tumors and metastases repeatedly over time, with reduced statistical bias $(13-16)$. However, ${ }^{18} \mathrm{~F}-\mathrm{FDG}$ is not specific for cancer cells; inflammatory foci, sarcoidosis, and active tuberculosis are also shown as ${ }^{18} \mathrm{~F}-\mathrm{FDG}-$ positive lesions. Because ${ }^{18} \mathrm{~F}$-FDG accumulation is equally intense, it is challenging to differentiate malignant from inflammatory lesions due to increased glucose metabolism rates $(17,18)$.

The positron emitter ${ }^{64} \mathrm{Cu}$ (half-life, $12.7 \mathrm{~h}$ ) has been explored for use in PET in numerous recent studies $(9,19)$. The well-established coordination chemistry of copper allows for its reaction with a wide variety of chelator systems that can potentially be linked to small-molecule peptides, antibodies, proteins, and nanoparticles (19). Compared with ${ }^{18} \mathrm{~F},{ }^{64} \mathrm{Cu}$ has a longer half-life as is compatible with the time required for the optimal biodistribution of slowerclearing agents, which require longer imaging times.

Hypericin is a potent naturally occurring photodynamic agent, inducing apoptosis or necrosis of cancer cells when combined with light (20). Because the compound showed a peculiar affinity for irreversibly damaged ischemic or necrotic tissues, hypericin has also been recognized as a nonporphyrin necrosis-avid agent (21). Radiolabeled derivatives of hypericin such as ${ }^{123}$ I-iodohypericin have been studied in animal models of hepatic and myocardial infarction, though their mechanisms of action are still unclear $(22,23)$. We hypothesized that hypericin derivatives can be used for early assessment of PTA-induced necrosis and that their affinity for necrosis could be attributed to their binding to phospholipids that normally reside in the interior of the cell membrane but are exposed to the exterior environment when the cell membrane is damaged, as in the case of necrosis. In this work, we report the synthesis and characterization of ${ }^{64} \mathrm{Cu}$-bis-DOTA-hypericin and its use in assessing necrotic response in BT474 breast tumor xenografts that have undergone PTA.

\section{MATERIALS AND METHODS}

\section{Synthesis, Characterization, and Radiolabeling of Bis-DOTA-Hypericin}

Supplemental Figure 1 (supplemental materials are available online only at http://jnm.snmjournals.org) shows the synthesis scheme for bis-DOTA-hypericin. Detailed synthetic procedures are also provided in the supplemental materials. For radiolabeling, ${ }^{64} \mathrm{CuCl}_{2}$ (18.5-148 MBq) in $0.1 \mathrm{M}$ sodium acetate ( $\mathrm{pH}$ 5.2) was added to $12.5 \mu \mathrm{g}$ of bis-DOTA-hypericin in water. The reaction mixture was incubated at $70^{\circ} \mathrm{C}$ for $45 \mathrm{~min}$. The progress of the reaction was monitored by reversed-phase high-performance liquid chromatography with a radio detector.

\section{Synthesis of CuS Nanoparticles}

A detailed procedure for the synthesis of citrate-coated $\mathrm{CuS}$ nanoparticles in water has been described previously (9). Briefly, $1 \mathrm{~mL}$ of sodium sulfide solution $\left(\mathrm{Na}_{2} \mathrm{~S}, 1 \mathrm{M}\right)$ under stirring at room temperature was added into $1,000 \mathrm{~mL}$ of an aqueous solution of $\mathrm{CuCl}_{2}(0.1345 \mathrm{~g}, 1 \mathrm{mmol})$ and sodium citrate $(0.2 \mathrm{~g}, 0.68$ mmol). The pale blue $\mathrm{CuCl}_{2}$ solution turned dark brown immediately after the sodium sulfide was added. Five minutes later, the reaction mixture was heated to $90^{\circ} \mathrm{C}$ and stirred for 15 min until a dark green solution was obtained. The mixture was transferred to ice-cold water. The citrate-coated nanoparticles were obtained and stored at $4{ }^{\circ} \mathrm{C}$. To introduce polyethylene glycol coating, about $1 \mathrm{mg}$ of sulfhydryl-polyethylene glycol (SH-PEG) was added into the citrate-CuS nanoparticle solution $\left(1.42 \times 10^{15}\right.$ nanoparticles in $1.0 \mathrm{~mL}$ of water). The reaction was allowed to proceed overnight at room temperature. Supplemental Figure 2 shows a transmission electron microscopy image and the absorption spectrum of citrate$\mathrm{CuS}$ nanoparticles.

\section{Cell Line and Animal Models}

To create the BT474 breast tumor xenografts, we used 6- to 8wk-old female nude mice (Charles River Laboratories). All animal experiments were conducted in accordance with the guidelines of the Institutional Animal Care and Use Committee. The human mammary cancer BT474 cell line was obtained from the American Type Culture Collection. The cells were maintained in Dulbecco's modified Eagle's medium (DMEM) and F-12 medium (Invitrogen Corp.) supplemented with $10 \%$ fetal bovine serum (FBS) (Hyclone) and $1 \%$ penicillin-streptomycin and were incubated at $37^{\circ} \mathrm{C}$ with $5 \% \mathrm{CO}_{2}$ and $100 \%$ humidity. One $17 \beta$-estradiol pellet $(5 \mathrm{mg} /$ pellet, catalog no. SE-121; Innovative Research of America) was implanted subcutaneously in the back of each mouse $1 \mathrm{~d}$ before subcutaneous injection of tumor cells $\left(1 \times 10^{7}\right.$ cells) in the right front flank. When the tumors reached approximately $8-10 \mathrm{~mm}$ in diameter, the mice were randomly divided into a treated group (TG) and nontreated group (N-TG; controls). All mice in the TG received an intratumoral injection of $10 \mu \mathrm{L}$ of $\mathrm{CuS}$ nanoparticle solution $\left(4 \times 10^{13}\right.$ nanoparticles $\left./ \mathrm{mL}\right)$, and their tumors were irradiated with an NIR laser $\left(808 \mathrm{~nm}, 12 \mathrm{~W} / \mathrm{cm}^{2}\right.$ for 
$3 \mathrm{~min}) 24 \mathrm{~h}$ later. The mice in both groups were intravenously injected with ${ }^{64} \mathrm{Cu}$-Bis-DOTA-hypericin $(24 \mathrm{~h}$ after laser treatment in the TG).

\section{Laser Treatment}

A continuous-wave GCSLX-05-1600m-1 fiber-coupled diode laser with a center wavelength of $808 \pm 10 \mathrm{~nm}$ was used. It was powered by a DH 1715A-5 dual-regulated power supply (15PLUS Laser; Diomed). A 5-m, 600- $\mu \mathrm{m}$ core BioTex LCM-001 optical fiber (BioTex Inc.) was used to transfer laser power from the laser unit to the target. The output power was independently calibrated using a handheld model 840-C optical power meter (Newport Corp.) and was found to be $1.5 \mathrm{~W}$ for a spot diameter of $4 \mathrm{~mm}$ $\left(\sim 12 \mathrm{~W} / \mathrm{cm}^{2}\right)$ and a 2-amp supply current. The end of the optical fiber was attached to a retort stand using a movable clamp and positioned directly above the tumor.

\section{In Vitro Study of PTA with CuS Nanoparticles in BT474 Cells}

BT474 cells were seeded onto a 96-well plate with a density of 10,000 cells per well $1 \mathrm{~d}$ before the experiment. Cells were washed 3 times with Hanks balanced salt solution (Sigma-Aldrich) and then were treated with $\mathrm{CuS}$ nanoparticles alone $(1 \mathrm{mM})$, NIR laser alone, or $\mathrm{CuS}$ nanoparticles followed by NIR laser $2 \mathrm{~h}$ after $\mathrm{CuS}$ nanoparticle treatment. Nontreated cells were used as a control. For laser treatment, cells were irradiated with a diode NIR laser (15PLUS Laser; Diomed) centered at $808 \mathrm{~nm}$ at an output power of $12 \mathrm{~W} / \mathrm{cm}^{2}$ for $3 \mathrm{~min}$. The laser was coupled to a 1-m-long, 2mm-core-diameter fiber, which delivered a circular laser beam (diameter, $4 \mathrm{~mm}$ ), covering the central area of the microplate well. After treatment, cells were resupplied with RPMI 1640 (Invitrogen) without phenol red containing $10 \%$ FBS. Twenty-four hours later, the cells were washed with Hanks balanced salt solution and stained with calcein AM for visualization of viable cells and with EthD-1 for visualization of dead cells according to the manufacturer's suggested protocol (Invitrogen). Cells were examined under an Axio Observer.Z1 fluorescence microscope (Carl Zeiss MicroImaging $\mathrm{GmbH}$ ). Experiments were performed in triplicate.

\section{Cell Uptake}

BT474 cells in a 12-well plate were incubated with approximately $3 \times 10^{11} \mathrm{CuS}$ nanoparticles $/ \mathrm{mL}$ in $0.2 \mathrm{~mL}$ of DMEM at $37^{\circ} \mathrm{C}$ for $2 \mathrm{~h}$. Cells were washed once with phosphate-buffered saline, and then DMEM supplemented with 10\% FBS without phenol red was added. Cells either were not treated with the NIR laser or were irradiated at a dose of $12 \mathrm{~W} / \mathrm{cm}^{2}$ for $3 \mathrm{~min}$. After irradiation, the cells were cultured with fresh complete DMEM supplemented with 10\% FBS for $24 \mathrm{~h}$. Each experiment was performed in triplicate. The cells were scraped and transferred into $2-\mathrm{mL}$ tubes and coincubated with $0.37 \mathrm{MBq} / \mu \mathrm{L}(10 \mu \mathrm{Ci} / \mu \mathrm{L})$ of ${ }^{64} \mathrm{Cu}$-bis-DOTA-hypericin at $37^{\circ} \mathrm{C}$ for $1 \mathrm{~h}$. Next, $500 \mu \mathrm{L}$ of a 75:25 mixture of silicon oil (density, 1.05; Sigma-Aldrich) and mineral oil (density, 0.872; Acros) were added into the cell suspension. The mixture was centrifuged at $14,000 \mathrm{rpm}$ for $10 \mathrm{~min}$. The tubes were frozen in liquid nitrogen, the bottom tips containing the cell pellet were cut off, and the cell pellets and supernatants were collected and counted for radioactivity. The data were expressed as activity ratios of the cell pellet to the medium ([cpm/ug of protein in pellet/cpm/ug of medium] $\times 100 \%)$.

\section{Preparation of Small Unilamellar Vesicles}

Small unilamellar vesicles were prepared as described previously (24). Briefly, rotary evaporation under reduced pressure of the chloroform phospholipid stock solution (Avanti Polar Lipids Inc.) resulted in a thin lipid film on the sides of a round-bottom flask. The lipid films were thoroughly dried to remove residual organic solvent by rotation under a vacuum for $2 \mathrm{~h}$. Hydration of each lipid film was achieved by the addition of $10 \mathrm{mM} \mathrm{N}$-(2hydroxyethyl)piperazine- $N^{\prime}$-(2-ethanesulfonic acid) buffer $(\mathrm{pH}$ 7.4) containing $2.5 \mathrm{mM} \mathrm{CaCl}_{2}$ and $100 \mathrm{mM} \mathrm{NaCl}$ to give a final $5 \mathrm{mM}$ concentration of phospholipid vesicles. This suspension was then thoroughly mixed for $2 \mathrm{~h}$ on a rotary evaporation system without a vacuum. The resultant hydrated vesicles were then stored on dry ice overnight. Before loading to the L1 chip surface, the vesicles were extruded 20 times through a $50-\mathrm{nm}$ polycarbonate filter using an extrusion apparatus to give small unilamellar vesicles composed of phosphatidylserine only, phosphatidylethanolamine only, or phosphatidylcholine only or composed of a mixture of phosphatidylcholine and phosphatidylethanolamine (phosphatidylethanolamine/phosphatidylcholine, 1:1).

\section{Surface Plasmon Resonance Measurements}

A Biacore 3000 apparatus (Biacore Life Sciences) equipped with an L1 chip was used for surface plasmon resonance measurements using $10 \mathrm{mM} N$-(2-hydroxyethyl)piperazine- $N^{\prime}$-(2ethanesulfonic acid) ( $\mathrm{pH} 7.4,100 \mathrm{mM} \mathrm{NaCl})$, with or without 2.5 $\mathrm{mM} \mathrm{CaCl} 2$ as the running buffer. The buffer solution was filtered through a $0.22-\mu \mathrm{m}$ filter and degassed thoroughly. The L1 chips were coated with vesicles by injecting $20 \mu \mathrm{L}$ of $5 \mathrm{mM}$ phospholipid vesicle suspension at a rate of $5 \mu \mathrm{L} / \mathrm{min}$ for $20 \mathrm{~min}$, conditioned with 3 consecutive injections of isopropanol/50 $\mathrm{mM} \mathrm{NaOH}$ $(2: 3, \mathrm{v} / \mathrm{v})$, each at $30 \mu \mathrm{L} / \mathrm{min}$ for $1 \mathrm{~min}$. Solutions of bis-DOTAhypericin at various concentrations in the running buffer were injected over the flow cells at a flow rate of $20 \mu \mathrm{L} / \mathrm{min}$ for predetermined periods. The bis-DOTA-hypericin solution was then replaced with the running buffer to allow it to dissociate. Binding levels expressed as a response unit (RU) were recorded for all injections before and after the onset of dissociation. The specific binding profiles of the peptides to phosphatidylserine were obtained by subtracting the response signal of the control flow cell coated with phosphatidylcholine from the total phosphatidylserine binding signal. The analysis was performed in duplicate at concentrations ranging from 0.325 to $25 \mu \mathrm{M}$. A sensorgram was obtained by plotting the RU against time. An increase in RU from the injection point and a decrease in RU from the beginning of the washing step, as measures of association and dissociation, respectively, were determined and used to compare binding affinities. After each injection-dissociation cycle, the flow cell surfaces were regenerated by injection of isopropanol and $50 \mathrm{mM} \mathrm{NaOH}$ solution.

\section{Small-Animal PET and Biodistribution}

An R4 microPET unit (Siemens Medical Solutions USA, Inc.), which has an approximate resolution of $2 \mathrm{~mm}$ in each axial direction, was used for imaging. After a tail vein injection of ${ }^{64} \mathrm{Cu}-$ bis-DOTA-hypericin (5.55-7.4 MBq/0.1 mL [150-200 $\mu \mathrm{Ci} / 0.1$ $\mathrm{mL}]$ ), a 20-min prone scan was obtained at 2, 6, and $24 \mathrm{~h}$ after injection. Mice were maintained under anesthesia with $1 \%-2 \%$ isoflurane, and a heating lamp was used to maintain their body temperature during acquisition. Small-animal PET images were reconstructed with the ordered-subsets expectation maximization algorithm using 16 subsets and 4 iterations.

Irregular 3-dimensional regions of interest were manually drawn around the edge of the tumor activity by visual inspection using ASIpro VM software (Analysis Tools and System Setup/ Diagnostics Tool; Siemens Medical Solutions USA). Separate 
regions of interest were drawn for each scan because the tumor size tended to change $24 \mathrm{~h}$ after treatment. The mean activities within the regions of interest were recorded. Assuming a tissue density of $1 \mathrm{~g} / \mathrm{mL}$, the regions of interest were converted to $\mathrm{MBq} / \mathrm{g}$ and then divided by the administered activity to obtain a percentage injected dose per gram of tissue $(\% \mathrm{ID} / \mathrm{g})$ derived from the imaging region of interest.

Immediately after the last imaging session at $24 \mathrm{~h}$ after injection, the mice were killed. Blood, heart, liver, spleen, kidney, lung, stomach, intestine, muscle, bone, brain, and tumor tissues were removed and weighed, and radioactivity was measured with a Cobra $\gamma$-counter (Packard Cobra). The uptake of ${ }^{64} \mathrm{Cu}$-labeled hypericin in the various organs was calculated as the $\% \mathrm{ID} / \mathrm{g}$.

\section{Histopathology and Autoradiography}

Of each tumor collected at $24 \mathrm{~h}$ after injection, one half was used to measure the radioactivity count and the other half was snap-frozen with optimum-cutting-temperature compound (Sakura Finetek) and sectioned into 6-8 consecutive 5- $\mu \mathrm{m}$ slices. One slice was stained with hematoxylin and eosin $(\mathrm{H} \& \mathrm{E})$, and the other slices were stained for autoradiography. For autoradiography, the slices were dried at $40^{\circ} \mathrm{C}$ in open air. The sections were then photographed and exposed on BAS-SR 2025 Fuji phosphorous film, and the film was scanned with the FLA5100 Multifunctional Imaging System (Fujifilm Medical Systems USA).

\section{Statistical Analysis}

Group variation was described as the mean \pm SD. Statistical analyses were performed to compare the uptake at different time points in the TG and N-TG at 2, 6, and $24 \mathrm{~h}$. Means were compared using 1-way ANOVA. A $P$ value of less than 0.05 was assigned statistical significance.

\section{RESULTS}

\section{${ }^{64} \mathrm{Cu}$ Labeling and Stability} of ${ }^{64} \mathrm{Cu}$-Bis-DOTA-Hypericin

The synthesis of bis-DOTA-hypericin and ${ }^{64} \mathrm{Cu}$-bisDOTA-hypericin is shown in Supplemental Figure 1A. Radio-high-performance liquid chromatography analysis showed that the labeling efficiency was $97.7 \%$. Supplemental Figures $1 \mathrm{~B}$ and $1 \mathrm{C}$ show high-performance liquid chromatograms of ${ }^{64} \mathrm{Cu}$-bis-DOTA-hypericin recorded using a sodium crystal radiodetector and ultraviolet-visible light detector at $254 \mathrm{~nm}$, confirming that the radiochemical purity of ${ }^{64} \mathrm{Cu}$-bis-DOTA-hypericin was greater than $95 \%$. The structure of the DOTA-hypericin was confirmed by mass spectrometry.

\section{In Vitro PTA Mediated with CuS Nanoparticles and Cell Uptake of ${ }^{64} \mathrm{Cu}$-Bis-DOTA-Hypericin}

Exposure of BT474 cells to both $\mathrm{CuS}$ nanoparticles and NIR laser caused significantly greater cell death than exposure to $\mathrm{CuS}$ nanoparticles alone or NIR laser alone. The membranes of cells treated with PTA were damaged, as indicated by the uptake of the red, cell-impermeable EthD-1 dye in the cells treated with $\mathrm{CuS}$ nanoparticles and NIR laser (Fig. 1A). Also, BT474 cells treated with $\mathrm{CuS}$ nanoparticles and irradiated with NIR laser had a significantly higher uptake of ${ }^{64} \mathrm{Cu}$-bis-DOTA-hypericin than cells exposed to $\mathrm{CuS}$ nanoparticles only (Fig. 1B). The uptake of ${ }^{64} \mathrm{Cu}$-bis-DOTA-hypericin in laser-treated dead cells was reduced by $54 \%$ in the presence of an excess amount of cold hypericin (Supplemental Fig. 3).

\section{Surface Plasmon Resonance Screening of Phosphatidylserine-Binding Peptides}

Figure 2 represents sensorgrams of bis-DOTA-hypericin used as an analyte obtained on a phosphatidylserine-coated L1 sensor chip (Fig. 2A) and a phosphatidylethanolaminephosphatidylcholine-coated L1 sensor chip (Fig. 2B). A summary of binding levels at the end of association and dissociation phases for bis-DOTA-hypericin is also presented in Figure 2. The surface plasmon resonance experiment showed that bis-DOTA-hypericin had a higher binding affinity to phosphatidylserine and phosphatidylethanolamine than to phosphatidylcholine.

\section{Small-Animal PET and Biodistribution}

All tumors in the PTA group were clearly visible at 2-24 $\mathrm{h}$ after injection of ${ }^{64} \mathrm{Cu}$-bis-DOTA-hypericin, whereas a rather low uptake of the radiotracer was seen in the N-TG at all time points. The highest uptake in the TG was observed

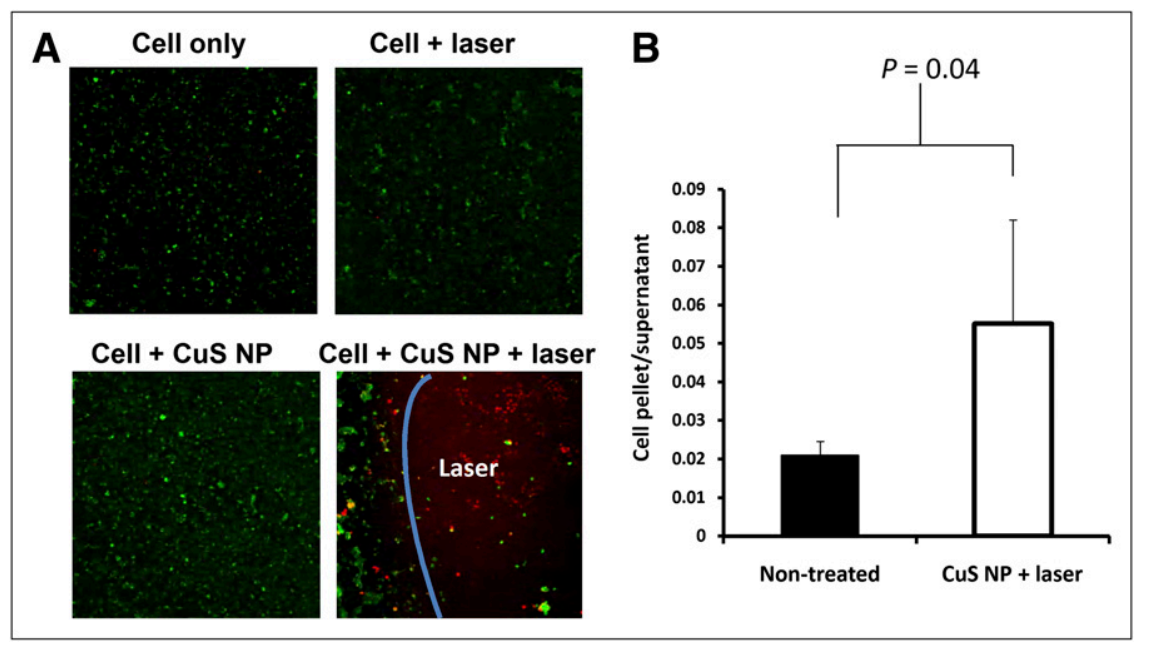

FIGURE 1. (A) In vitro PTA mediated with CuS nanoparticles. BT474 cells were exposed to CuS nanoparticles (1 $\mathrm{mM})$ alone, NIR laser alone (808 nm, $15 \mathrm{~mW} / \mathrm{cm}^{2}$, $3 \mathrm{~min}$ ), or combination of CuS nanoparticles and NIR laser. Cells exposed to both CuS nanoparticles and laser caused extensive cell death. Right side of curve indicates area irradiated with NIR laser; left side indicates area treated with CuS nanoparticle but not irradiated with laser. (B) Uptake of ${ }^{64} \mathrm{Cu}$-BisDOTA-hypericin in BT474 cells. Radiotracer had significantly higher uptake in treated cells than in nontreated cells. NP = nanoparticles. 


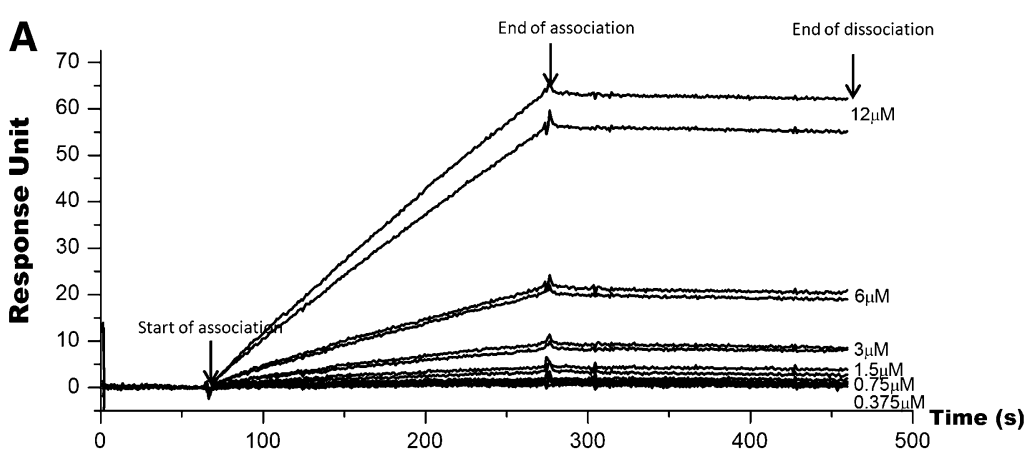

FIGURE 2. Surface plasmon resonance sensorgrams of bis-DOTA-hypericin obtained on sensor chips immobilized with phosphatidylserine (A) and phosphatidylethanolamine (B). Sensorgrams were obtained by subtracting $\mathrm{RU}$ of control flow cell coated with phosphatidylcholine from total binding signal from flow cells coated with either phosphatidylserine or phosphatidylethanolamine-phosphatidylcholine. Binding profiles were performed in duplicate at bis-DOTAhypericin concentrations ranging from 0.375 to $12 \mu \mathrm{M}$.

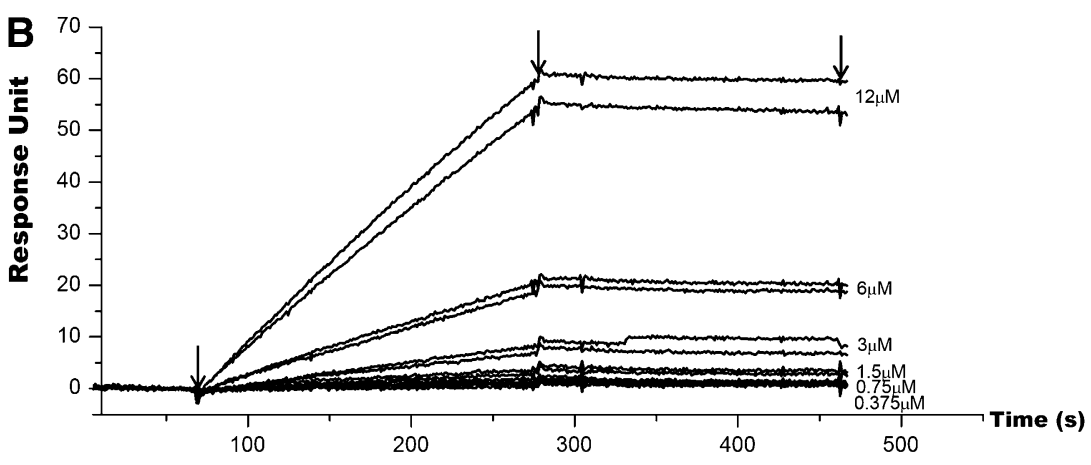

at $24 \mathrm{~h}$ after injection (Fig. 3A). Quantitative imaging analysis showed a significantly higher tumor uptake of ${ }^{64} \mathrm{Cu}-$ bis-DOTA-hypericin in the TG mice than in the N-TG mice $(P<0.05)$. The tumor uptake values at 2,6 , and $24 \mathrm{~h}$ after
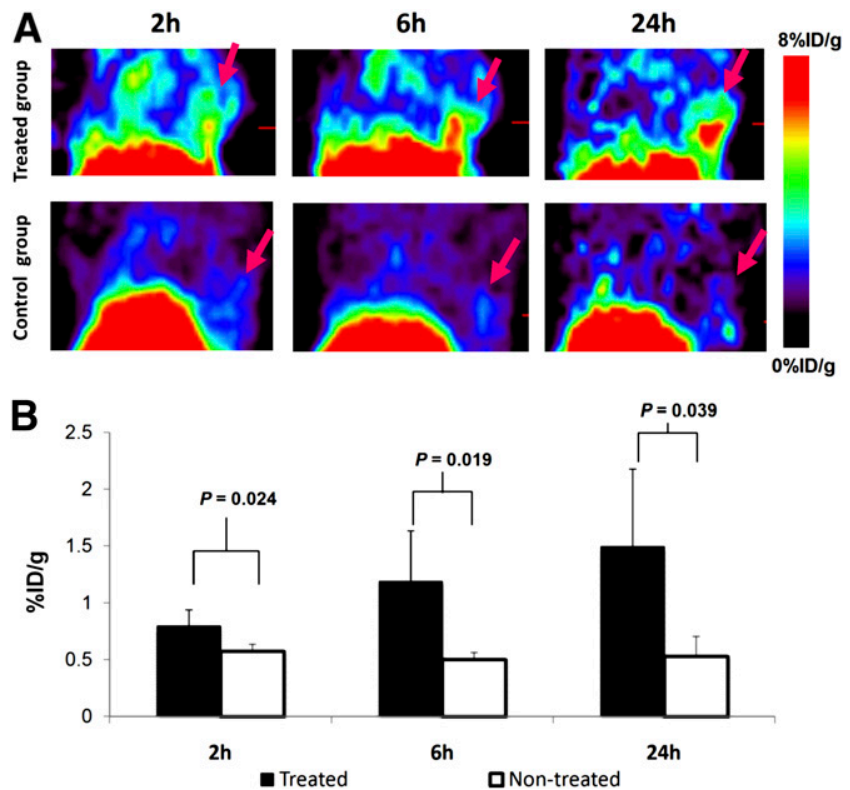

FIGURE 3. (A) Representative small-animal PET images of mice treated with CuS nanoparticles (intratumoral injection, $10 \mu \mathrm{L}, 4 \times$ $10^{13}$ nanoparticles $\left./ \mathrm{mL}\right)$, followed by NIR laser $\left(808 \mathrm{~nm}, 12 \mathrm{~W} / \mathrm{cm}^{2}\right.$, $3 \mathrm{~min}$ ), and nontreated control mice after intravenous injection of ${ }^{64} \mathrm{Cu}$-Bis-DOTA-hypericin (5.55-7.4 MBq). (B) Tumor uptake values obtained from quantitative imaging analysis. Treated tumors had significantly higher uptake than nontreated tumors at 2, 6, and $24 \mathrm{~h}$ after radiotracer injection. Data are expressed as mean and SD $(n=4-5)$. injection in the TG were $0.80 \pm 0.14 \% \mathrm{ID} / \mathrm{g}, 1.19 \pm 0.45$ $\% \mathrm{ID} / \mathrm{g}$, and $1.49 \pm 0.68 \% \mathrm{ID} / \mathrm{g}$, respectively. The values at 2,6 , and $24 \mathrm{~h}$ after injection in the N-TG were $0.57 \pm 0.06$ $\% \mathrm{ID} / \mathrm{g}, 0.50 \pm 0.63 \% \mathrm{ID} / \mathrm{g}$, and $0.53 \pm 0.18 \% \mathrm{ID} / \mathrm{g}$, respectively (Fig. 3B).

The biodistribution data were consistent with the PET findings (Fig. 4). At $24 \mathrm{~h}$ after injection, the tumor uptake was significantly higher $(1.71 \pm 0.43 \% \mathrm{ID} / \mathrm{g})$ in the TG mice than in the N-TG mice $(0.76 \pm 0.19 \% \mathrm{ID} / \mathrm{g})(P=$ 0.017). Liver and kidney had the highest uptake of ${ }^{64} \mathrm{Cu}-$ bis-DOTA-hypericin. There were no differences in other organs between the TG and N-TG mice.

\section{Correlation of High-Uptake Areas on Small-Animal PET with H\&E Findings}

In conventional histology ( $\mathrm{H} \& \mathrm{E})$, tumors undergoing $\mathrm{CuS}$ nanoparticle and NIR treatment showed signs of cell damage or injury of various extents. Tumor cells displayed nuclear pyknosis and cytoplasmic edema, with patches of eosinophilic tumor necrosis evident. Thromboses of the larger adjacent vessels were found on the tumor-muscle border. The untreated tumors were composed of viable hematoxylinophilic malignant cells in large quantity. Figure 5 compares autoradiographs of tumors from mice treated with PTA and untreated mice at $24 \mathrm{~h}$ after ${ }^{64} \mathrm{Cu}$-bis-DOTAhypericin injection. ${ }^{64} \mathrm{Cu}$-bis-DOTA-hypericin showed higher uptake in treated tumors (Fig. 5A), which correlated with areas of injured tumor cells on histologic slides stained with H\&E. In contrast, the tumors from nontreated mice had relatively lower uptake of ${ }^{64} \mathrm{Cu}$-bis-DOTA-hypericin, which corresponded with the presence of a large number of viable tumor cells (Fig. 5B). 


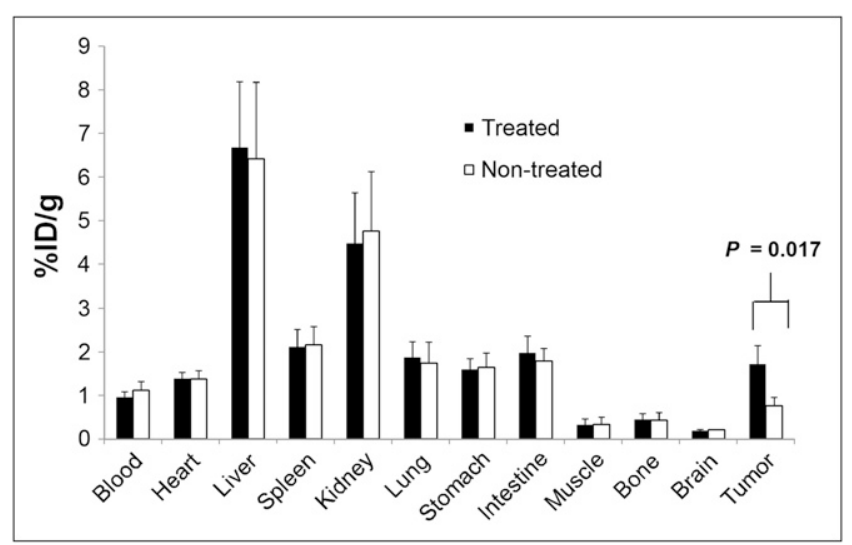

FIGURE 4. Biodistribution of ${ }^{64} \mathrm{Cu}-\mathrm{Bis}-\mathrm{DOTA}$-hypericin at $24 \mathrm{~h}$ after injection. Data are expressed as mean \pm SD $(n=4-5)$.

\section{DISCUSSION}

Our study demonstrates that ${ }^{64} \mathrm{Cu}$-bis-DOTA-hypericin can be used to assess therapeutic response induced by PTA. A significantly higher accumulation of ${ }^{64} \mathrm{Cu}$-bis-DOTA-hypericin was observed in tumors treated with $\mathrm{CuS}$ nanoparticles plus NIR laser than in nontreated tumors. ${ }^{64} \mathrm{Cu}$-bis-DOTA-hypericin small-animal PET could differentiate treated from nontreated tumors as early as $24 \mathrm{~h}$ after PTA treatment (Figs. 3 and 4).

In PTA, photothermal coupling agents are used to mediate increases in the local temperatures far above the threshold $\left(\sim 54^{\circ} \mathrm{C}\right)$ at which irreversible cell death occurs. Thermal ablation kills cells directly by inducing cellular injury, leading to necrosis (3). To ensure the safety and efficacy of such a procedure, the nanoparticles have to be delivered to the target volume, and the extent of therapy and early response to treatment have to be monitored properly. Therefore, successful translation of PTA into the clinic will require the accurate visualization and quantification of the accumulation of photothermal-conducting nanoparticles in the tumors for pretreatment planning, noninvasive monitoring of the spatiotemporal heat profile and response to therapy in a given target volume, and selective delivery of nanoparticles to the tumor.

The accumulation of nanoparticles in tumors has been noninvasively evaluated by PET using photothermal- conducting nanoparticles labeled with the positron-emitting radionuclide ${ }^{64} \mathrm{Cu}(25)$. It has also been proposed that MRI may be used to detect the intratumoral distribution of photothermal-conducting nanoparticles using gold nanostructures encapsulated with superparamagnetic iron oxide nanoparticles (26). MRI can also provide real-time temperature-sensitive imaging feedback during therapy (4).

In this work, we addressed the problem associated with noninvasive assessment of therapeutic response induced by PTA. Semiconductor CuS nanoparticles that showed a strong absorption in the NIR region, high photothermal conducting efficiency, low cytotoxicity, and small particle size were chosen as the PTA agent $(9,10)$. Irradiation of tumor cells exposed to CuS nanoparticles with an NIR laser caused marked cell death in BT474 tumors both in vitro and in vivo, characterized by cell membrane damage (Fig. 1) and extensive tumor damage (Fig. 5).

Hypericin is a naturally occurring photosensitizer derived from St. John's wort (27). As a photodynamic sensitizer, hypericin is able to generate superoxide anion and singlet oxygen with a high quantum yield. When combined with light, hypericin can effectively induce apoptosis or necrosis of cancer cells. Although not evaluated in this work, ${ }^{64} \mathrm{Cu}$-bis-DOTA-hypericin may also be an efficient photodynamic agent and thus may be suitable for both diagnostic and therapeutic applications. Van de Putte et al. $(21,28)$ investigated the distribution of hypericin in a murine liver tumor model and found that hypericin was a necrosis-avid agent. They showed that hypericin specifically stained necrotic tissue by interacting with necrotic cellular debris. Our experiment with PTA-treated BT474 tumors suggested that ${ }^{64} \mathrm{Cu}$-bis-DOTA-hypericin as a hypericin derivative is associated with injured rather than viable tumor cells. Therefore, ${ }^{64} \mathrm{Cu}$-bis-DOTA-hypericin is a new radiotracer suitable for noninvasive imaging of PTAinduced tumor damage by small-animal PET.

Although the affinity of hypericin to necrotic tissues has been reported, little is known about the mechanism of this affinity. The membrane of the cell is made up of 4 principal phospholipid components: phosphatidylcholine, phosphatidylethanolamine, phosphatidylserine, and sphingomyelin.
A

Treated tumor

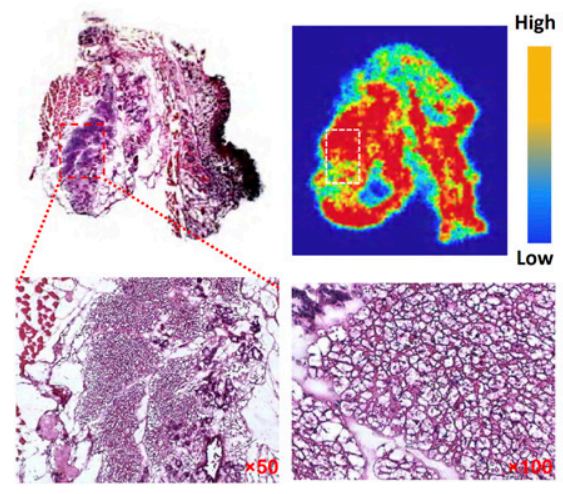

B Non-treated tumor

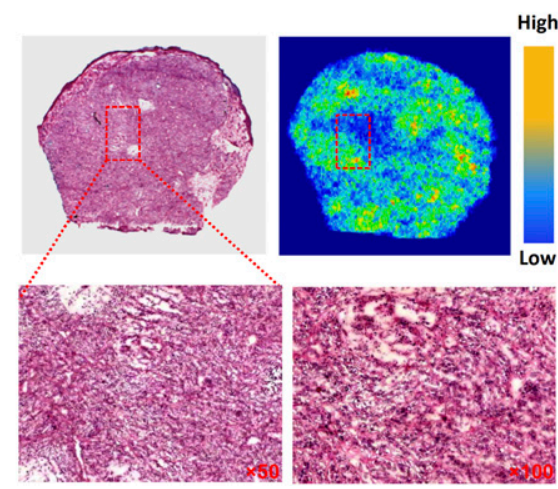

FIGURE 5. Autoradiographs and photographs of corresponding H\&E-stained tumor section from treated tumors $(A)$ and nontreated tumors (B). ${ }^{64} \mathrm{Cu}$-bis-DOTA-hypericin showed higher uptake in treated tumors, corresponding with areas of injured tumor cells. 
These 4 phospholipids are distributed between the 2 monolayers of the membrane in an asymmetric fashion, with phosphatidylcholine and sphingomyelin largely populating the extracellular leaflet and phosphatidylethanolamine and phosphatidylserine restricted primarily to the inner leaflet (29). There is abundant evidence suggesting that phosphatidylserine externalization is a contributing factor to the recognition of dead and dying cells by macrophages (30). Because inflammatory cells are reported to express phosphatidylserine on their cell surface (31-33), and inflammation and malignancy often go together, ${ }^{64} \mathrm{Cu}$-bis-DOTA-hypericin may also be used to assess tumor inflammation. Our finding that bis-DOTA-hypericin had differential binding to phosphatidylserine and phosphatidylethanolamine, as compared with phosphatidylcholine (Fig. 2), the most common and abundant phosphatidyl lipid on the surface of the plasma membrane, suggests that selective binding to phosphatidylserine and phosphatidylethanolamine in damaged cells with disintegrated cell membranes may be one of the contributing factors responsible for the affinity of hypericin for necrosis.

\section{CONCLUSION}

Our studies demonstrate that ${ }^{64} \mathrm{Cu}$-bis-DOTA-hypericin has a high binding affinity to damaged tumor cells and, thus, a potential use in the noninvasive assessment of early tumor response to PTA with PET. The mechanism of the affinity of hypericin to necrotic cells can be explained, at least in part, by the loss of the cell membrane integrity and subsequent exposure of phosphatidylserine and phosphatidylethanolamine to the extracellular fluid and by selective binding of hypericin to phosphatidylserine-phosphatidylethanolamine, as compared with phosphatidylcholine. The ability to monitor response to $\mathrm{CuS}$ nanoparticle-mediated PTA should provide the opportunity for the noninvasive assessment of response to PTA and other thermal ablation techniques.

\section{DISCLOSURE STATEMENT}

The costs of publication of this article were defrayed in part by the payment of page charges. Therefore, and solely to indicate this fact, this article is hereby marked "advertisement" in accordance with 18 USC section 1734.

\section{ACKNOWLEDGMENTS}

We thank Dawn Chalaire for editing the article. This work was funded in part by the John S. Dunn Foundation and the National Natural Science Foundation of China (grant 30830038), the Shanghai Leading Academic Discipline Project (grant S30203), and the European Commission Project Asia-Link (CfP 2006-EuropeAid/123738/C/ ACT/Multi-Proposal No. 128-498/111).

\section{REFERENCES}

1. Fiedler VU, Schwarzmaier HJ, Eickmeyer F, Muller FP, Schoepp C, Verreet PR. Laser-induced interstitial thermotherapy of liver metastases in an interventional 0.5 Tesla MRI system: technique and first clinical experiences. J Magn Reson Imaging. 2001;13:729-737.
2. Vogel A, Venugopalan V. Mechanisms of pulsed laser ablation of biological tissues. Chem Rev. 2003;103:577-644.

3. Dewey WC. Arrhenius relationships from the molecule and cell to the clinic. Int J Hyperthermia. 1994;10:457-483.

4. Hirsch LR, Stafford RJ, Bankson JA, et al. Nanoshell-mediated near-infrared thermal therapy of tumors under magnetic resonance guidance. Proc Natl Acad Sci USA. 2003;100:13549-13554.

5. Loo C, Lin A, Hirsch L, et al. Nanoshell-enabled photonics-based imaging and therapy of cancer. Technol Cancer Res Treat. 2004;3:33-40.

6. O'Neal DP, Hirsch LR, Halas NJ, Payne JD, West JL. Photo-thermal tumor ablation in mice using near infrared-absorbing nanoparticles. Cancer Lett. 2004;209:171-176.

7. El-Sayed IH, Huang X, El-Sayed MA. Selective laser photo-thermal therapy of epithelial carcinoma using anti-EGFR antibody conjugated gold nanoparticles. Cancer Lett. 2006;239:129-135.

8. Skrabalak SE, Au L, Lu X, Li X, Xia Y. Gold nanocages for cancer detection and treatment. Nanomedicine (Lond). 2007;2:657-668.

9. Zhou M, Zhang R, Huang M, et al. A Chelator-free multifunctional $\left[{ }^{64} \mathrm{Cu}\right] \mathrm{CuS}$ nanoparticle platform for simultaneous micro-PET/CT imaging and photothermal ablation therapy. J Am Chem Soc. 2010;132:15351-15358.

10. Li Y, Lu W, Huang Q, Huang M, Li C, Chen W. CuS nanoparticles for photothermal ablation of tumor cells. Nanomedicine (Lond). 2010;5:1161-1171.

11. Contractor KB, Aboagye EO. Monitoring predominantly cytostatic treatment response with ${ }^{18}$ F-FDG PET. J Nucl Med. 2009;50(suppl 1):97S-105S.

12. Saif MW, Tzannou I, Makrilia N, Syrigos K. Role and cost effectiveness of PET/CT in management of patients with cancer. Yale J Biol Med. 2010;83:5365.

13. Frangioni JV. New technologies for human cancer imaging. J Clin Oncol. 2008;26:4012-4021.

14. Aukema TS, Kappers I, Valdes Olmos RA, et al. Is ${ }^{18}$ F-FDG PET/CT useful for the early prediction of histopathologic response to neoadjuvant erlotinib in patients with non-small cell lung cancer?. J Nucl Med. 2010;51:1344-1348.

15. Song SL, Liu JJ, Huang G, et al. Changes in ${ }^{18} \mathrm{~F}-\mathrm{FDG}$ uptake within minutes after chemotherapy in a rabbit VX2 tumor model. J Nucl Med. 2008;49:303-309.

16. Song SL, Deng C, Wen LF, et al. ${ }^{18}$ F-FDG PET/CT-related metabolic parameters and their value in early prediction of chemotherapy response in a VX2 tumor model. Nucl Med Biol. 2010;37:327-333.

17. Rosenbaum SJ, Lind T, Antoch G, Bockisch A. False-positive FDG PET uptake: the role of PET/CT. Eur Radiol. 2006;16:1054-1065.

18. Siegel BA, Dehdashti F. Oncologic PET/CT: current status and controversies. Eur Radiol. 2005;15(suppl 4):D127-D132.

19. Anderson CJ, Ferdani R. Copper-64 radiopharmaceuticals for PET imaging of cancer: advances in preclinical and clinical research. Cancer Biother Radiopharm. 2009;24:379-393.

20. Karioti A, Bilia AR. Hypericins as potential leads for new therapeutics. Int J Mol Sci. 2010;11:562-594.

21. Van de Putte M, Wang H, Chen F, De Witte PA, Ni Y. Hypericin as a marker for determination of tissue viability after radiofrequency ablation in a murine liver tumor model. Oncol Rep. 2008;19:927-932.

22. Fonge H, Vunckx K, Wang H, et al. Non-invasive detection and quantification of acute myocardial infarction in rabbits using mono- $\left[{ }^{123} \mathrm{I}\right]$ iodohypericin microSPECT. Eur Heart J. 2008;29:260-269.

23. Ni Y, Huyghe D, Verbeke K, et al. First preclinical evaluation of mono- $\left[{ }^{123} \mathrm{I}\right]$ iodohypericin as a necrosis-avid tracer agent. Eur J Nucl Med Mol Imaging. 2006;33:595-601.

24. Vanderheyden JL, Liu G, He J, Patel B, Tait JF, Hnatowich DJ. Evaluation of ${ }^{99 m}$ Tc-MAG3-annexin V: influence of the chelate on in vitro and in vivo properties in mice. Nucl Med Biol. 2006;33:135-144.

25. Lu W, Zhang G, Zhang R, et al. Tumor site-specific silencing of NF-кB p65 by targeted hollow gold nanosphere-mediated photothermal transfection. Cancer Res. 2010;70:3177-3188.

26. Melancon M, Lu W, Li C. Gold-based magneto/optical nanostructures: challenges for in vivo applications in cancer diagnostics and therapy. Mater Res Bull. 2009;34:415-421.

27. Schempp CM, Winghofer B, Langheinrich M, Schopf E, Simon JC. Hypericin levels in human serum and interstitial skin blister fluid after oral single-dose and steady-state administration of Hypericum perforatum extract (St. John's wort). Skin Pharmacol Appl Skin Physiol. 1999;12:299-304.

28. Van de Putte M, Wang H, Chen F, de Witte PA, Ni Y. Hypericin as a marker for determination of tissue viability after intratumoral ethanol injection in a murine liver tumor model. Acad Radiol. 2008;15:107-113.

29. van den Boom MA, Wassink MG, Westerman J, et al. In vivo turnover of phospholipids in rabbit erythrocytes. Biochim Biophys Acta. 1994;1215:314320 . 
30. Li MO, Sarkisian MR, Mehal WZ, Rakic P, Flavell RA. Phosphatidylserine receptor is required for clearance of apoptotic cells. Science. 2003;302: 1560-1563.

31. Fadok VA, de Cathelineau A, Daleke DL, Henson PM, Bratton DL. Loss of phospholipid asymmetry and surface exposure of phosphatidylserine is required for phagocytosis of apoptotic cells by macrophages and fibroblasts. J Biol Chem. 2001;276:1071-1077.
32. Gaipl US, Beyer TD, Baumann I, et al. Exposure of anionic phospholipids serves as anti-inflammatory and immunosuppressive signal: implications for antiphospholipid syndrome and systemic lupus erythematosus. Immunobiology. 2003; 207:73-81.

33. Fadeel B, Xue D, Kagan V. Programmed cell clearance: molecular regulation of the elimination of apoptotic cell corpses and its role in the resolution of inflammation. Biochem Biophys Res Commun. 2010;396:7-10. 